\title{
Angiomyolipoma with caval extension and regional nodal involvement: Aggressive behaviour or just rare natural history? Case report and review of literature
}

\author{
Kamaljot Singh Kaler, MD; ${ }^{*}$ Rebekah Rittberg; ${ }^{\dagger}$ Darrel E. Drachenberg, MD, FRCSC \\ *Department of Surgery, Section of Urology, University of Manitoba, Winnipeg, MB; †Faculty of Medicine, University of Manitoba, Winnipeg, MB
}

Cite as: Can Urol Assoc J 2014;8(3-4):e276-8. http://dx.doi.org/10.5489/cuaj.1781 Published online April 14, 2014.

\section{Abstract}

Renal angiomyolipoma ( $\mathrm{AML}$ ) is predominantly a non-aggressive benign tumour. Cases of more aggressive AMLs are present in the literature. We present 2 cases of aggressive AML behaviour. The first case is an AML with vascular extension in a young female and the second case is of $\mathrm{AML}$ found in regional lymph nodes in a female with a left renal $\mathrm{AML}$ and renal cell carcinoma.

\section{Introduction}

Renal angiomyolipoma (AML) is a solid mesenchymal tumour composed of smooth muscle cells, mature adipose tissue and aneurysmal blood vessels. ${ }^{1}$ It is primarily a benign non-aggressive tumour typically requiring intervention in symptomatic patients or when the tumour diameter exceeds $4 \mathrm{~cm}$ as the risk of hemorrhage increases. ${ }^{2}$ However, there are cases of more aggressive AML behaviour. Here 2 cases of atypical AML behaviour are presented: inferior vena cava tumour extension and positive regional lymph nodes.

\section{Case 1}

A 27-year-old female presented with right upper quadrant pain. The patient's religious beliefs precluded the possibility of blood transfusion and she refused absolutely receiving any blood products. Initially thought to be biliary colic, we performed an ultrasonography and found a right renal mass. Subsequent computer tomography $(\mathrm{CT})$ and magnetic resonance imaging (MRI) demonstrated a fat-containing mass with enhancing stromal components in the right kidney with extension into the right renal vein and inferior vena cava (IVC) with termination in the intrahepatic IVC portion (Fig. 1). She had no history of tuberous sclerosis complex. Preoperatively, the patient was assessed by Blood Conservation Service (Winnipeg Regional Health Authority) and given Eprex (Janssen, epoetin alfa) and Fragmin (Eisai, dalteparin sodium injection) to optimize hemoglobin and minimize emboli risk, respectively. She underwent a right radical nephrectomy, adrenal sparing, and IVC tumour thrombectomy with $100 \mathrm{cc}$ of blood loss and no complications.

Pathology demonstrated a renal AML $(10 \times 7 \times 6 \mathrm{~cm})$ with renal vein and IVC involvement with AML. The mass and thrombus were contiguous on gross pathology, and thrombus consistent with AML on micro pathology. The mass contained a mixture of adipose tissue, smooth muscle type cells and vascular channels (Fig. 2). The epitheloid cells demonstrated mild atypia and occasional mitotic figures, but no necrosis or transformation into sarcoma or carcinoma. Surgical and Gerota's fascia margins were negative. The remaining kidney tissue was normal.

\section{Case 2}

A 67-year-old female presented with an incidental left renal mass found on ultrasonography. CT demonstrated a $6.4-\mathrm{cm}$ renal mass with potential extension into the left renal vein consistent with renal cell carcinoma (RCC). Ultrasonography also detected a contralateral renal mass measuring $7 \times 7 \times 6 \mathrm{~mm}$ suggestive of small cyst or AML. There was no evidence of metastasis. She underwent a left laparoscopic radical nephrectomy with lymphadenectomy without complications.

Pathology demonstrated the mass as clear cell RCC in the upper pole of the left kidney with extension into the left renal vein. The tumour measured $5 \times 3.5 \mathrm{~cm}$ with pathologic stage of T3a. Additionally, there was an AML adjacent and intimately associated with the RCC. Para-aortic lymph node was negative for RCC, but positive for AML. Postoperative follow-up at 6 months revealed no local recurrence. 


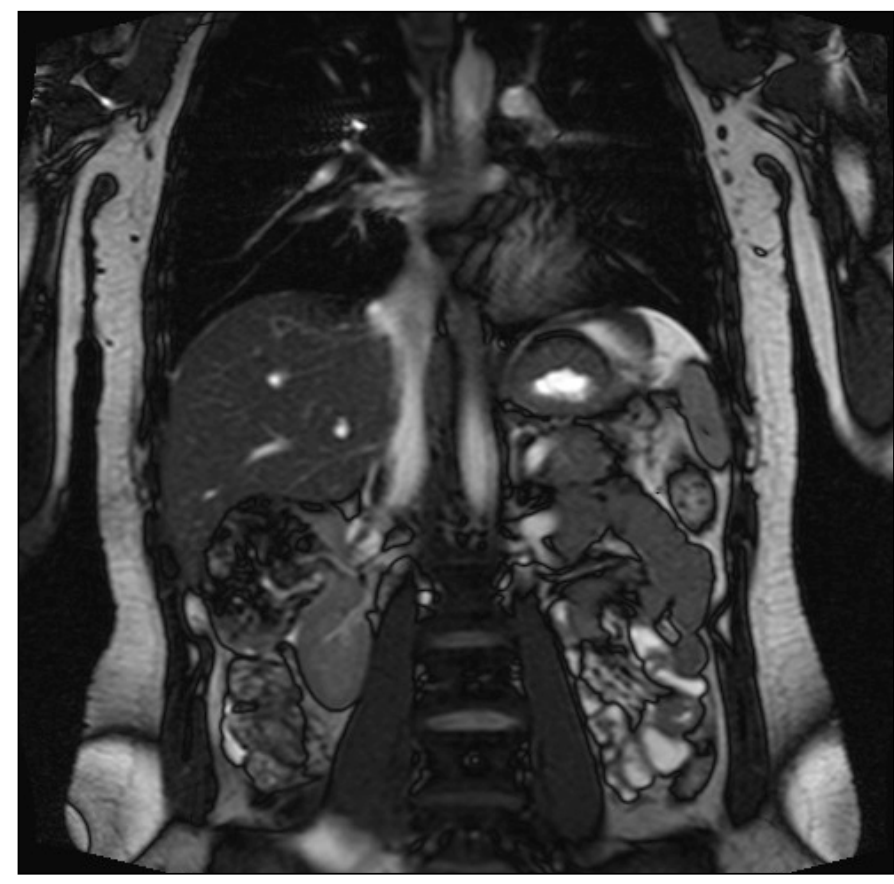

Fig. 1. Coronal magnetic resonance imaging demonstrating right angiomyolipoma with renal vein and inferior vena cava extension. Note the filling defect in the inferior vena cava representing tumour thrombus to the intrahepatic cava.

\section{Discussion}

Perivascular epithelioid cell neoplasm (PEComa) is a tumour family with mesenchymal origin derived from perivascular epithelioid cells. ${ }^{3}$ Renal AML, a PEComa, is the most common mesenchymal neoplasm found in $0.1 \%$ to $0.3 \%$ of the general population with 2 distinct groups: classic triphasic AML and monotypic epithelioid AML. ${ }^{4,5}$

Classic triphasic AML is a benign, slow growing tumour composed of smooth muscle, adipose tissue and blood vessels. ${ }^{6}$ It is primarily found in the kidney, but has been identified in the spleen, liver, uterus and fallopian tubes. ${ }^{7}$ In a few cases, AMLs have been found with perirenal tissue invasion, positive regional lymph nodes, IVC extension, and occasionally extending into the right atrium. ${ }^{8,9}$

Classic AMLs are sporadic in $80 \%$ of cases, while the remaining $20 \%$ are associated with genetic syndromes, such as tuberous sclerosis complex, an autosomal dominant disease. In both cases, there is female and right kidney predominance. Tuberous sclerosis complex AMLs present earlier in life, with a faster growth rate and increased risk of bilateralilty. ${ }^{10} \mathrm{AMLs}$ are also found in patients with lymphangioleiomyomatosis, a condition characterized by an infiltration of disorganized smooth muscle fibres throughout the lung. About $50 \%$ of patients with lymphangioleiomyomatosis will develop renal AML. ${ }^{5}$

Epithelioid AML, the second group of renal AMLs, are composed of sheets of epithelioid cells that can behave

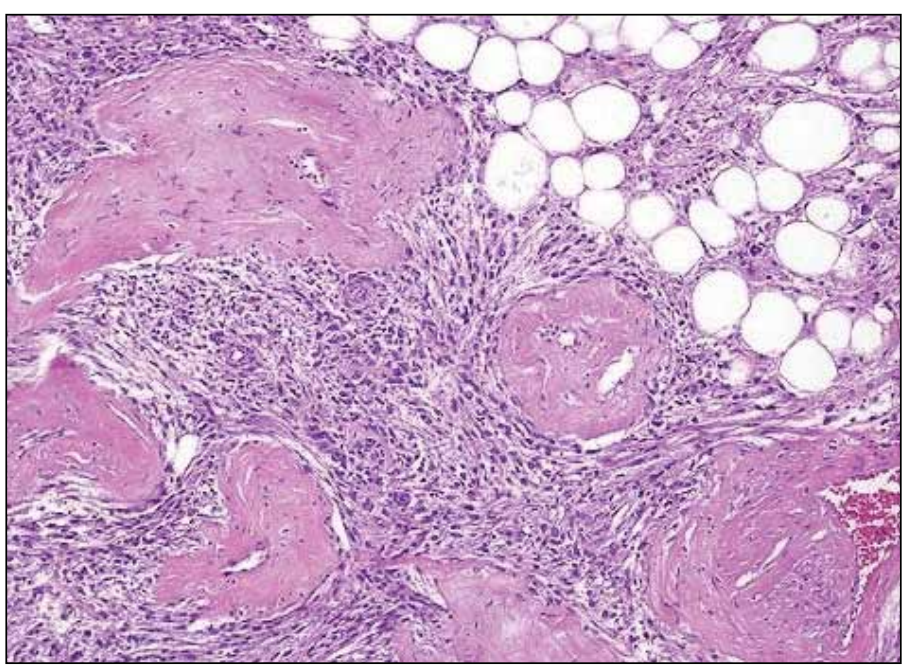

Fig. 2. Pathology from a 27 -year-old female demonstrating renal angiomyolipoma. Note the triphasic appearance that is pathognomonic, including vessel, fat, and smooth muscle in specimen.

aggressively, with the potential for metastasis and resultant adjuvant therapy. ${ }^{11}$ Moreover, some retrospective pathologic studies have illustrated that previously diagnosed RCC were actually epithelioid AML. ${ }^{12}$

AML lymph node involvement has been found in perihilar and retroperitoneal lymph nodes. ${ }^{13}$ This is suggestive of multifocal growth as opposed to metastases because of the benign nature of these tumours and the absence of local disease recurrence following a complete resection. ${ }^{14}$ Since lymph node dissection is rarely performed with this tumour

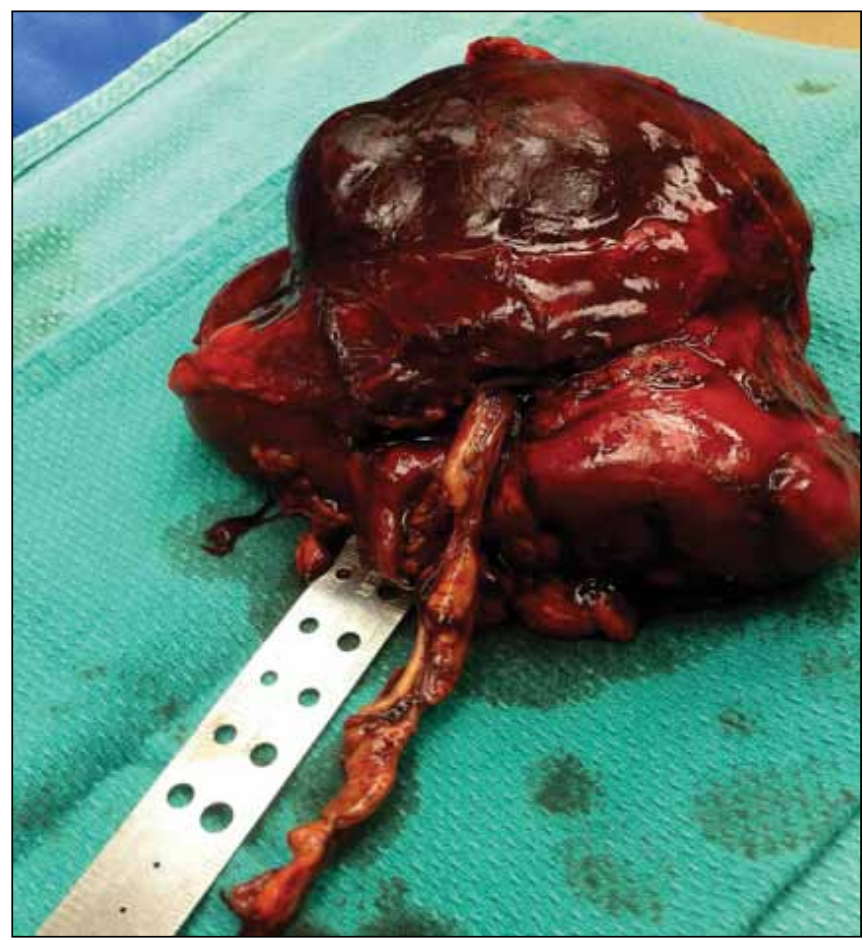

Fig. 3. Gross specimen showing kidney and attached venous thrombus. 
Kaler et al.

type, the true prevalence of positive lymph nodes in patients with renal $\mathrm{AML}$ is unknown. ${ }^{8}$

Accelerated AML growth can be observed during pregnancy and hormonal treatment. ${ }^{3}$ It is hypothesized that progesterone stimulates $\mathrm{AML}$ growth through $\mathrm{AML}$ cell hormone receptor expression. ${ }^{15}$ Additionally, during pregnancy there is an increased AML rupture rate due to both increased blood volume and renal perfusion. ${ }^{7}$ In a female of childbearing age, surgical removal of a tumour that has previously hemorrhaged or a tumour that is greater than $4 \mathrm{~cm}$ should be done prior to pregnancy. ${ }^{15}$

As stated, earlier guidelines for renal AML management, such as those proposed by Oesterling and colleagues, are based on tumour size and the presence of symptoms. ${ }^{2}$ However, with an atypical AML presentation this management may not apply. As with the case of vascular invasion, early surgical intervention is critical because a cardiopulmonary tumour embolus may be fatal.

Renal AML treatment includes partial or radical nephrectomy or transarterial selective embolization. ${ }^{10}$ The primary morbidity of AML is hemorrhage and renal failure. With increasing AML size, micro- and macro-aneurysms develop with the potential to rupture causing retroperitoneal hemorrhage or hematuria. Similarly, with increasing tumour size, renal tissue is compromised which could lead to renal failure. ${ }^{6}$

\section{Conclusion}

AMLs present as a disease spectrum both clinically and pathologically. Typically AMLs are benign; however, here we presented 2 cases of atypical AML behaviour. Neither case was consistent with the more aggressive epithelioid AML type or tuberous sclerosis complex. However, both cases showcased atypical AML behaviour.

Competing interests: Dr. Kaler and Dr. Rittberg declare no competing financial or personal interests. Dr. Drachenberg has attended Advisory Boards for Astellas and Janssen and has been a speaker for Amgen and Actavis (formerly Watson). He has also been an investigator in clinical trials run by Cancer Care Manitoba (CCMB)
This paper has been peer-reviewed.

\section{References}

1. Prasad SR, Surabhi VR, Menias CO, et al. Benign renal neoplasms in adults: Cross-sectional imaging findings. AJR Am J Roentgenol 2008; 190:158-64. http://dx.doi.org/10.2214/AJR.07.2724

2. Oesterling J, Fishman E, Goldman S, et al. The management of renal angiomyolipoma. J Urology 1986:135:1121-4.

3. Mehta V, Venkataraman $G$, Antic $T$, et al. Renal angiomyolipoma, fat-poor variant-a clinicopathologic mimicker of malignancy. Virchows Arch 2013;463:41-6. http://dx.doi.org/10.1007/s00428-013-1432-2

4. Bharwani N, Christmas T, Jameson C, et al. Epithelioid angiomyolipoma: Imaging appearances. Br J Radiol 2009;82:e249-52. http://dx.doi.org/10.1259/bir/27259024

5. Ryu JH, Hartman TE, Torres VE, et al. Frequency of undiagnosed cystic lung disease in patients with sporadic renal angiomyolipomas. Chest 2012;141:163-8. http://dx.doi.org/10.1378/chest.11-0669

6. Bissler JJ, Kingswood JC. Renal angiomyolipomata. Kidney Int 2004;66:924-34. http://dx.doi. org/10.1111/j.1523-1755.2004.00838.x

7. Zapardiel I, Delafuente-Valero J, Bajo-Arenas J. Renal angiomyolipoma during pregnancy: review of the literature. Gynecol Obstet Invest 2011;72:217-9. http://dx.doi.org/10.1159/000329328

8. Sant G, Ucci A, Meares E. Multicentric angiomyolipoma: Renal and lymph node involvement. Urology 1986;28:111-3. http://dx.doi.org/10.1016/0090-4295(86)90098-1

9. Mittal V, Aulakh BS, Daga G. Benign renal angiomyolipoma with inferior vena cava thrombosis. Urology 2011;77:1503-6. http://dx.doi.org/10.1016/i.urology.2011.01.039

10. Seyam RM, Bissada NK, Kattan SA, et al. Changing trends in presentation, diagnosis and management of renal angiomyolipoma: Comparison of sporadic and tuberous sclerosis complex-associated forms. Urology 2008;72:1077-82. http://dx.doi.org/10.1016/i.urology.2008.07.049

11. He W, Cheville JC, Sadow PM, et al. Epithelioid angiomyolipoma of the kidney: Pathological features and clinical outcome in a series of consecutively resected tumors. Modern Path 2013;26:1355-64. http:// dx.doi.org/10.1038/modpathol.2013.72. Epub 2013 Apr 19.

12. Pea $M$, Bonetti $F$, Martignoni $G$, et al. Apparent renal cell carcinomas in tuberous sclerosis are heterogeneous: The identification of malignant epithelioid angiomyolipoma. Am I Surg Pathol 1998;22:180-7. htrp://dx.doi.org/10.1097/00000478-199802000-00005

13. Köksal IT, Tunç M, Kiliçaslan I, et al. Lymph nodal involvement by renal angiomyolipoma. Int I Urol 2000;7:386-9. http://dx.doi.org/10.1046/i.1442-2042.2000.00213.x

14. Lin WY, Chuang CK, Ng KF, et al. Renal angiomyolipoma with lymph node involvement: A case report and literature review. Chang Gung Med I 2003;26:607-10.

15. Lopater J, Hartung 0 , Bretelle $F$, et al. Management of angiomyolipoma vena cava thrombus during pregnancy. Obstet Gynecol 2011;117:440-3. http://dx.doi.org/10.1097/A0G.0b013e3181edbc56

Correspondence: Dr. Darrel Drachenberg, Director of Research, Section of Urology and Manitoba Prostate Centre, Chair of Genitourinary Oncology Disease site group, Cancer Care Manitoba, Department of Surgery, University of Manitoba, Winnipeg, MB; ddrachenberg@sbgh.mb.ca 